\title{
Role of the Direct and Indirect Pathways for Glycogen Synthesis in Rat Liver in the Postprandial State
}

\author{
Ming-Ta Huang and Richard L. Veech \\ Laboratory of Metabolism and Molecular Biology, National Institute on Alcohol Abuse and Alcoholism, Rockville, Maryland 20852
}

\begin{abstract}
The pathway for hepatic glycogen synthesis in the postprandial state was studied in meal-fed rats chronically cannulated in the portal vein. Plasma glucose concentration in the portal vein was found to be $4.50 \pm 1.01 \mathrm{mM}(\operatorname{mean} \pm \mathrm{SE} ; n=3)$ before a meal and $11.54 \pm 0.70 \mathrm{mM}($ mean $\pm S E ; n=4)$ after a meal in rats meal-fed a diet consisting of $100 \%$ commercial rat chow for $7 \mathrm{~d}$. The hepatic-portal difference of plasma glucose concentration showed that liver released glucose in the fasted state and either extracted or released glucose after feeding depending on plasma glucose concentration in the portal vein. The concentration of portal vein glucose at which liver changes from glucose releasing to glucose uptake was $8 \mathrm{mM}$, the $K_{\mathrm{m}}$ of glucokinase [E.C. 2.7.1.12]. The rate of glycogen synthesis in liver during meal-feeding was found to be $\sim 1 \mu \mathrm{mol}$ glucosyl $\mathrm{U} / \mathrm{g}$ wet $\mathrm{wt} / \mathrm{min}$ in rats meal-fed a $50 \%$ glucose supplemented chow diet. The relative importance of the direct vs. indirect pathway for the replenishment of hepatic glycogen was determined by the incorporation of $\left[3-{ }^{3} \mathrm{H}, \mathrm{U}-{ }^{14} \mathrm{C}\right]$ glucose into liver glycogen. Labeled glucose was injected into the portal vein at the end of meal-feeding. The ratio of ${ }^{3} \mathrm{H} /{ }^{14} \mathrm{C}$ in the glucosyl units of glycogen was found to be $83-92 \%$ of the ratio in liver free glucose six minutes after the injection, indicating that the majority of exogenous glucose incorporated into glycogen did not go through glycolysis. The percent contribution of the direct versus indirect pathway was quantitated from the difference in the relative specific activity $(\mathrm{RSA})$ of $\left[{ }^{3} \mathrm{H}\right]$ and $\left[{ }^{14} \mathrm{C}\right]-$ glycogen in rats infused with $\left[3-{ }^{3} \mathrm{H}, \mathrm{U}-{ }^{14} \mathrm{C}\right]$ glucose. No significant difference was found between the RSA of $\left[{ }^{3} \mathrm{H}\right] \mathrm{glycogen}$ and $\left[{ }^{14} \mathrm{Clglycogen}\right.$, indicating further that the pathway for glycogen synthesis in liver from exogenous glucose is from the direct pathway. Our results do not support the thesis that the majority of liver glycogen is synthesized from glucose-6-phosphate derived from gluconeogenesis. Reasons for the discrepancy between current findings and other reports supporting the indirect pathway for glycogen synthesis in the liver are discussed.
\end{abstract}

\section{Introduction}

Glycogen in liver is synthesized from glucose-6-phosphate via glucose-1-phosphate and UDP-glucose. Glucose-6-phosphate can be formed in the liver either by the direct phosphorylation of glucose or via gluconeogenesis from three-carbon intermediates $\left(C_{3}\right)$. A widely accepted view is that in most mammals

Address reprint requests to Dr. Huang.

Received for publication 6 February 1987 and in revised form 27 July 1987.

The Journal of Clinical Investigation, Inc.

Volume 81, March 1988, 872-878 including human, postprandial glycogenesis from exogenous glucose primarily proceeds directly through glucose-6-phosphate derived from the phosphorylation of glucose (1-5). Recently however, Katz and McGarry (6) and Katz et al. (7) postulate that liver can not utilize glucose efficiently, and that postprandial glycogen replenishment is mostly brought about through the operation of an indirect pathway that requires prior degradation of glucose to compounds located at the level of triose phosphates or lower down the glycolytic pathway. The carbon from these intermediates of glycolysis is then converted via gluconeogenesis to glucose-6-phosphate, glucose-1-phosphate and ultimately ends up in the glucosyl units of newly synthesized glycogen. This metabolic route for hepatic glycogen synthesis has been termed the "indirect pathway" $(6,7)$ to distinguish it from the more conventional "direct pathway". Further, the futile breaking down of glucosyl units followed by their resynthesis from the indirect pathway has been cited as evidence for either intracellular compartmentation of pathways or functional "zonation" of liver (8).

Experimental evidence favoring the indirect pathway for glycogen synthesis in liver in vivo was first reported by Newgard, McGarry, and co-workers (9-11). These authors used an isotopic technique similar to that used frequently in studies of futile cycling in glucose metabolism (12). In their studies, rats were fitted with intragastric, femoral artery and/or femoral vein catheters. In one experiment $(9),\left[3-{ }^{3} \mathrm{H}, \mathrm{U}-{ }^{14} \mathrm{C}\right]$ glucose was infused intragastrically or intravenously $20 \mathrm{~h}$ after the implantation of cannulae. The retention of tritium relative to ${ }^{14} \mathrm{C}$ in liver glycogen was determined. Since tritium from $\left[3-{ }^{3} \mathrm{H}\right]-$ glucose would be released in triose phosphate isomerase reaction while ${ }^{14} \mathrm{C}$ radioactivity would remain in $\mathrm{C}_{3}$ intermediates (lactate, pyruvate and alanine) that can be reincorporated in the glucosyl units of glycogen via gluconeogenesis, a decrease in the ratio of ${ }^{3} \mathrm{H} /{ }^{14} \mathrm{C}$ in glycogen would reflect glycogen synthesis from the indirect pathway. Newgard et al. (9) reported that the ratio of ${ }^{3} \mathrm{H} /{ }^{14} \mathrm{C}$ in liver glycogen is reduced to $40-65 \%$ compared with that in the infused glucose. The percent contribution of the direct versus indirect pathway was quantitated from the relative specific activity (RSA) ${ }^{1}$ of $\left[{ }^{3} \mathrm{H}\right]$ glycogen. The RSA of glycogen was calculated by dividing the specific activity of glycogen-glucose by that of glucose in the infusing solution (9). Since the range of the RSA of $\left[{ }^{3} \mathrm{H}\right]$ glycogen found to be $12-28 \%$, it was concluded that 72 to $88 \%$ of glycogen synthesized in the liver is through the indirect pathway in liver. In another experiment (10), $\left[3-{ }^{3} \mathrm{H}, \mathrm{U}-{ }^{14} \mathrm{C}\right]$ glucose was replaced by $\left[1-{ }^{14} \mathrm{C}\right]$ glucose. Glycogen synthesis from the direct pathway retains ${ }^{14} \mathrm{C}$-radioactivity in the same carbon position in glucosyl units of glycogen, whereas glycogen synthesis from the indirect pathway results in the translocation (scrambling) of the radioactivity to the lower half of the glucose molecule in

1. Abbreviation used in this paper: RSA, relative specific activity. 
glycogen. Newgard et al. reported that only $\sim 50 \%$ of the radioactivity in glucosyl units of glycogen was retained in the $\mathrm{C}-1$ position (10), indicating also that extensive breakdown of the glucose molecule occurs during glycogenesis.

Using nuclear magnetic resonance technique and $\left[1-{ }^{13} \mathrm{C}\right]-$ glucose, Shulman et al. (13) determined the percent enrichment of ${ }^{13} \mathrm{C}$ in $\mathrm{C}-1$ of the glucosyl units in glycogen and glucose in the portal vein after an intragastric gavage of $\left[1-{ }^{13} \mathrm{C}\right]-$ glucose. Unlike Newgard et al. $(9,10)$ who reported significant scrambling of glucose carbons, Shulman et al. (13) found that $82-87 \%$ of the ${ }^{13} \mathrm{C}$ in liver glycogen is located at C-1 of glucosyl units in glycogen. This data show that prior breakdown of the glucose molecule into $C_{3}$ intermediates and subsequent synthesis of glucose-6-phosphate from these intermediates are not obligatory for the glycogen synthesis in liver. Shulman et al. also concluded from the RSA of glycogen that the direct pathway can account for no more than one third of the total glycogen synthesis in the liver. More recently, Lang et al. (14) also reported that at physiological concentration of plasma glucose, the indirect pathway for glycogen synthesis predominates. In human, there is also indication supporting the indirect pathway for glycogen synthesis in the liver (15).

In their reviews $(6,7)$ on the "glucose paradox," Katz and McGarry have noted the difficulty in measuring metabolite concentrations in the portal vein $(6,7)$ and the scarcity of this information in the literature. They cited the work of Rémésy et al. (16) who showed glucose uptake in livers of anesthetized rats fed a high carbohydrate diet having a portal vein glucose concentration of $8.8 \mathrm{mM}$. We have recently developed a method to chronically cannulate the portal vein of meal-fed rats to allow glucose concentration to be measured across the liver during meal feeding. It is the aim of the current study to reexamine the role of the direct versus indirect pathway for the replenishment of hepatic glycogen in meal-fed animals. Using an isotopic method similar to that of Newgard et al. (9) and Lang et al. (14), we found that glycogen synthesis in liver from the infused glucose is derived mostly from the direct pathway. Previous reports $(9-11,13,14)$ showing the predominance of the indirect pathway in liver glycogen synthesis were attributed to inappropriate method of calculation.

\section{Methods}

Animals. Male Wistar rats (250-300 g) were anesthetized with nembutal $(50 \mathrm{mg} / \mathrm{kg}$ ), the abdominal cavity was opened, and a cannula (PE 10) was inserted in the portal vein through the lower pancreatoduodenal vein (17). Thus, the circulation through the lower pancreatoduodenal vein is blocked by cannulation but hormonal supplies from the pancreas or pancreatic islet can still be achieved through the superior pancreatoduodenal vein. Hormonal supplies are not affected because in rats the superior and inferior pancreatoduodenal veins are not united (17). The suprahepatic cannula (PE 10) was inserted through the external jugular vein and extended through the atrium to a point just below the diaphragm. Both cannulae were exteriorized subcutaneously in the interscapular region. The cannulae were filled with heparin and were protected by rodent jackets (Harvard Apparatus Corp., Natick, MA) for the duration of the experiment. The cannulated rats were kept individually in metabolic cages where they could move freely. Meal feeding from 8:00 to 10:00 a.m. with diet indicated was initiated on the second day after the surgery. Unoperated animals for the determination of glycogen synthesis were caged in groups of three and were meal-fed a diet containing 50\% ground chow and 50\% glucose from 8:00 to 10:00 a.m. for $5 \mathrm{~d}$.
Hepatic extraction of glucose. Blood samples $(0.3 \mathrm{ml})$ were taken simultaneously from the portal and suprahepatic cannulae on days 1 , 3,5 , and 7 after the initiation of the meal-feeding schedule before and after meal or during feeding as required. Plasma glucose concentration was measured enzymatically by spectrophotometric assay (18).

Glycogen synthesis in liver. To determine the rate of hepatic glycogenesis, one group of unoperated rats meal-fed glucose-supplemented diet was sacrificed at 8:00 a.m. before meal-feeding. The second and third groups of rats on the same dietary regimen were sacrificed 1 and 2 $h$ later after the initiation of feeding. Livers were freeze-clamped and glycogen content was determined according to Watanabe and Passonneau (19). Glycogen in liver $(\sim 0.2 \mathrm{~g})$ was precipitated by heating for 15 min at $85^{\circ} \mathrm{C}$ with $20 \% \mathrm{KOH}$ in $65 \%$ ethanol. The precipitates were washed with chloroform-methanol (1:1) and were dissolved in $1.0 \mathrm{ml}$ of $1.5 \mathrm{~N}$ acetic acid. After adjusting the $\mathrm{pH}$ to 4.5 with $\mathrm{NaOH}$, glycogen in the solution was hydrolyzed by incubating with amyloglucosidase for $1 \mathrm{~h}$. Glucose produced was assayed by spectrophotometric method (18). The incorporation of labeled glucose into glycogen was performed in cannulated rats 5 to $9 \mathrm{~d}$ after the initiation of meal-feeding schedule. A bolus of $\left[3-{ }^{3} \mathrm{H}, \mathrm{U}-{ }^{14} \mathrm{C}\right]$ glucose $(100 \mu \mathrm{Ci} / 10 \mu \mathrm{Ci} ; 2.3 \mu \mathrm{mol})$ in $100 \mu \mathrm{l}$ saline was injected into the portal vein at the end of mealfeeding. $5 \mathrm{~min}$ after the injection, blood samples were taken from the portal and suprahepatic cannulae. Livers were freeze-clamped 6 min after the injection. Glycogen was isolated and assayed as described.

Intravenous infusion of $\left[3-{ }^{3} \mathrm{H}, \mathrm{U}-{ }^{14} \mathrm{C}\right]$ glucose. In other experiments, $\left[3-{ }^{3} \mathrm{H}, \mathrm{U}-{ }^{14} \mathrm{C}\right.$ ]glucose were infused into the suprahepatic cannulae of a group of rats cannulated and starved overnight. Blood samples were taken from the portal vein periodically. At the end of three hours, liver were freeze-clamped. Labeled glucose in plasma and liver were isolated by ion exchange chromatography (20). Two columns were arranged in tandem, the first contained $3 \mathrm{ml}$ each of Dowex AG 1 resin in formate form and Dowex 50 in $\mathrm{H}^{+}$form, the second contained $3 \mathrm{ml}$ of Dowex AG 1 resin in borate form. Labeled glucose was eluted from the borate column by $5 \mathrm{ml} 1 \mathrm{~N} \mathrm{HCl}$ after the tandem columns were washed with $10 \mathrm{ml}$ of water and separated. Glycogen in liver were isolated and hydrolyzed as described. Radioactive glucose liberated from liver glycogen was also isolated by ion-exchange chromatography (20).

Materials. Enzymes for metabolites assay were obtained from Boeringer Mannheim (Indianapolis, IN). Isotopes were obtained from New England Nuclear (Boston, MA). The specific activity for $\left[3-{ }^{3} \mathrm{H}\right]-$ glucose was $13.5 \mathrm{Ci} / \mathrm{mmol}$; for $\left[\mathrm{U}-{ }^{14} \mathrm{C}\right.$ ]glucose was $4.43 \mathrm{mCi} / \mathrm{mmol}$.

\section{Results}

Body weight and food intake. Our surgical method to cannulate the portal and hepatic veins is different from those described in the literature (21-23). Since we do not insert the cannula directly into the portal vein, circulation through the latter during the operation is not disrupted. We are the first to describe that rats can be trained to meal-feed with cannulae implanted in the portal vein and suprahepatic veins. The status of animals were, therefore, monitored daily postsurgically. Changes in daily food intake and body weight were measured (Table I). In the first $2 \mathrm{~d}$ after the surgery, weight loss and appetite suppression in the cannulated rats were evident. Cannulated rats resumed eating on the third day after the surgery. From the fourth day on, the amount of food consumed and the change in body weight in the cannulated rats are comparable to that of unoperated, meal-fed rats.

Hepatic extraction of glucose. Portal vein plasma glucose concentration increased significantly after meal feeding. In rats meal-fed a diet consisting of $100 \%$ of rat chow for $7 \mathrm{~d}$, plasma glucose concentration in the portal vein was found to be $4.50 \pm 1.01 \mathrm{mM}(\operatorname{mean} \pm \mathrm{SE} ; n=3)$ before meal and increase 
Table I. Daily Food Intake and Change in Body Weight in Chronically Cannulated and Unoperated Rats*

\begin{tabular}{|c|c|c|c|c|c|c|}
\hline & \multicolumn{6}{|c|}{ Days on meal feeding } \\
\hline & 1 & 2 & 3 & 4 & 5 & 6 \\
\hline \multicolumn{7}{|l|}{ A Cannulated rats } \\
\hline change in body wt. $(g)$ & ND & $-15.3 \pm 2.3$ & $-10.3 \pm 0.6$ & $-1.7 \pm 0.9$ & $3.5 \pm 2.0$ & $2.7 \pm 0.9$ \\
\hline food intake $(g)^{\ddagger}$ & 0 & $1.7 \pm 0.9$ & $5.7 \pm 0.6$ & $10.8 \pm 0.7$ & $13.0 \pm 1.5$ & $11.8 \pm 0.8$ \\
\hline \multicolumn{7}{|l|}{ B Unoperated rats } \\
\hline change in body wt. $(g)$ & ND & $-8.7 \pm 2.1$ & $-3.7 \pm 0.7$ & $1.2 \pm 1.5$ & $-2.6 \pm 1.7$ & \\
\hline food intake $(g)^{\S}$ & $7.6 \pm 1.1$ & $11.2 \pm 1.8$ & $13.9 \pm 3.3$ & $13.2 \pm 1.5$ & $11.5 \pm 0.6$ & \\
\hline
\end{tabular}

* Meal feeding with 50\% glucose supplemented chow diet from 8:00 to 10:00 a.m. daily.

* Rats were implanted with intraportal and suprahepatic cannulae as described in Methods. Starting from the second day after the operation, rats were put on meal feeding.

${ }^{8}$ Rats were housed three in a cage.

to $11.54 \pm 0.70 \mathrm{mM}$ (mean $\pm \mathrm{SE} ; n=4$ ) after feeding. The ability of liver to extract glucose was found to be dependent on portal vein glucose concentration. As shown in Fig. 1, plasma glucose concentration in mixed hepatic blood for the most part is higher than that in the portal blood before daily feeding, indicating that in the absence of ingested food, liver releases glucose in most cases as would be expected. Liver either released or extracted glucose at the end of meal feeding, depending on the amount of food they consumed which varied from 0 to $\sim 13 \mathrm{~g}$ during the $7 \mathrm{~d}$ postoperative period (Table I). The difference in plasma glucose concentration in the portal and hepatic veins is highly correlated with plasma glucose concentration in the portal vein (Fig. 2). Liver changes its status from a glucose releasing organ to glucose uptake organ at a portal plasma glucose concentration of $8 \mathrm{mM}$ (Fig. 2).

Hepatic balance of glucose during meal-feeding. Glucose concentrations in blood sampled from the portal and suprahepatic cannulae during the first hour of meal-feeding were determined (Fig. 3). The animals were meal-fed with $100 \%$ rat chow for $6 \mathrm{~d}$. Plasma glucose concentration was determined on the seventh day. Fasting plasma glucose concentration in the suprahepatic vein appeared to be slightly higher than that in the portal vein (Fig. 3). Plasma glucose concentration in the portal and suprahepatic veins increased rapidly as soon as the animal started eating, indicating that the absorption of glucose

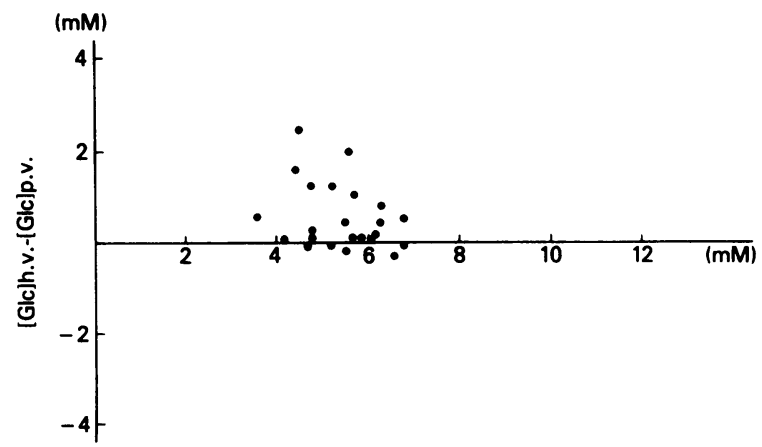

Figure 1. Difference in plasma glucose concentration [glc] in hepatic vein (h.v.) and portal vein (p.v.) vs. portal plasma glucose concentration before meal feeding. Mixed hepatic and portal blood were sampled from implanted cannulae on days $1,3,5$, and 7 after surgery before meal feeding. from the ingested complex carbohydrates in the diet is very rapid. The gradient of plasma glucose concentration in the portal and suprahepatic veins was also achieved early. $5 \mathrm{~min}$ after the initiation of eating, the difference between plasma glucose concentration in the portal and hepatic vein became significant (Fig. 3). This difference persisted throughout the entire period of observation.

Glycogen synthesis in liver. The rate of glycogen synthesis in meal-fed rats was determined in a group of unoperated rats on a $50 \%$ chow and $50 \%$ glucose diet. Before daily feeding, significant residual glycogen was found in livers of rats fed the glucose supplemented diet (Fig. 4). Glycogen content increased over the $2-\mathrm{h}$ meal-feeding period. The rate of glucose deposition in liver glycogen was estimated to be $57.7 \mu \mathrm{mol}$ glucosyl U/g wet wt per h (Fig. 4).

Glycogen synthesis from intraportally injected $\left[3-{ }^{3} H, U-\right.$ ${ }^{14} \mathrm{C}$ ] glucose. The incorporation of radioactive glucose into liver glycogen was determined in a group of cannulated rats on

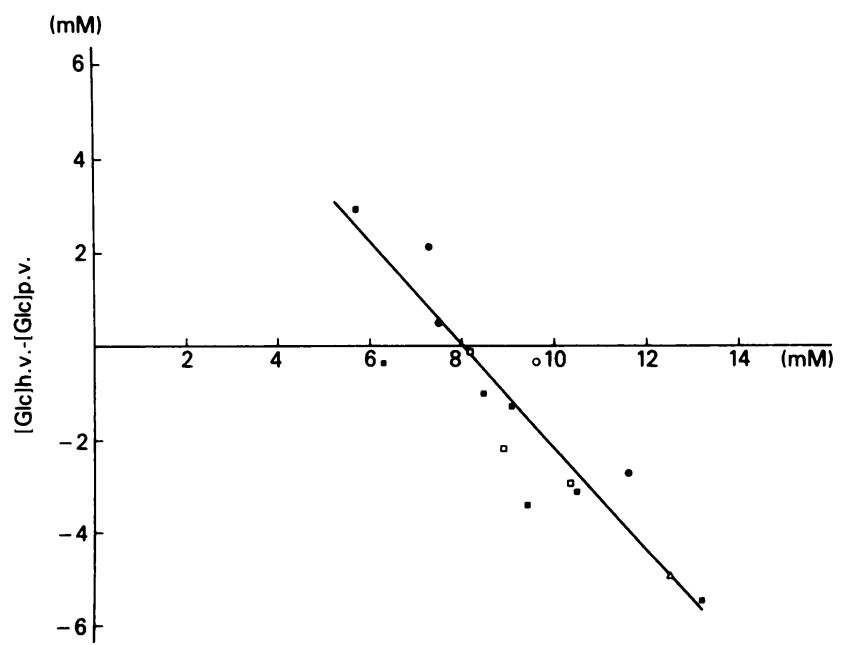

Figure 2. Difference in plasma glucose concentration [glc] in hepatic vein (h.v.) and portal vein (p.v.) vs. portal plasma glucose concentration after meal feeding. Rats were fed diets of $100 \%$ ground chow (a), $50 \%$ chow $+50 \%$ glucose $(\Delta), 50 \%$ chow $+50 \%$ fructose $(\bullet), 50 \%$ chow $+25 \%$ glucose $+25 \%$ fructose ( $\square$ ), and $50 \%$ chow $+50 \%$ sucrose (o). Plasma samples were taken after meal feeding. The correlation coefficient of the linear regression was $r^{2}=0.77 ; P<0.002$. 


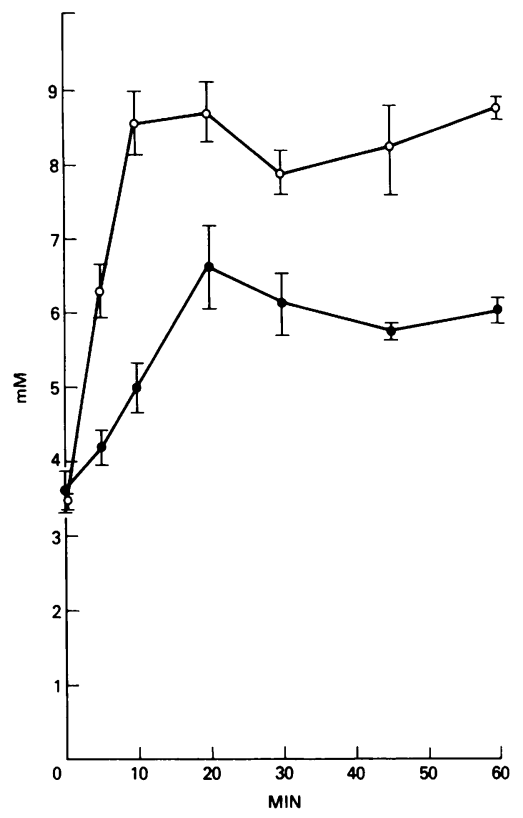

Figure 3. Changes in plasma glucose concentration in the portal (o) and mixed hepatic blood (•) during meal feeding. Rats were meal-fed a $100 \%$ rat chow diet for $6 \mathrm{~d}$. The experiment was performed on the seventh day during meal-feeding with the same diet. Data were mean $\pm S E$ of three experiments.

meal-feeding schedule fed $100 \%$ chow or $50 \%$ chow $+50 \%$ glucose for at least $5 \mathrm{~d}$ (Table II). A tracer dose of [3- ${ }^{3} \mathrm{H}, \mathrm{U}-$ ${ }^{14} \mathrm{Clglucose}$ was injected into the portal vein at the end of meal and the incorporation of radioactivity from glucose into glycogen was determined six minutes after the injection. As shown in Table II, the ratio of ${ }^{3} \mathrm{H} /{ }^{14} \mathrm{C}$ in liver glycogen was $\sim 83$ and $92 \%$ of that found in liver free glucose for rats maintained on $100 \%$ chow and $50 \%$ glucose supplemented chow diet, respectively. These results indicated that the majority of the exogenous glucose incorporated in liver glycogen did not go through triose phosphate isomerase and $\mathrm{C}_{3}$ intermediates. Supplementation of glucose in the diet resulted in 1.6 times more glycogen synthesized and 1.13 times higher ${ }^{3} \mathrm{H} /{ }^{14} \mathrm{C}$ ratio in glycogen, indicating further that glucose can be directly utilized for hepatic glycogenesis immediately following phosphorylation in liver (Table II).

Glycogen synthesis from intravenously infused $\left[3-{ }^{3} \mathrm{H}, \mathrm{U}\right.$ ${ }^{14} \mathrm{C}$ ]glucose. The incorporation of glucose infused intravenously into liver glycogen was also determined. Rats were in-

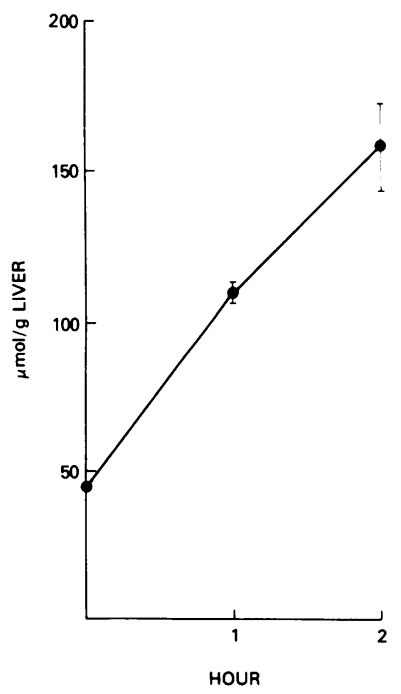

Figure 4. Glycogen accumulation (in glucosyl units) in rats meal-fed with $50 \%$ glucose supplemented chow diets. Data were mean $\pm \mathrm{SE}$; $n=3$. fused with $\left[3-{ }^{3} \mathrm{H}, \mathrm{U}-{ }^{14} \mathrm{C}\right]$ glucose intravenously at a rate of 1350 $\mu \mathrm{mol} / \mathrm{h}$ per $100 \mathrm{~g}(\sim 243 \mathrm{mg} / \mathrm{h}$ per $100 \mathrm{~g})$, a rate similar to that used by Newgard et al. (9) or Lang et al. (14). Plasma glucose concentration in the portal vein increases in response to intravenous feeding of glucose. The increase in plasma glucose concentration leveled off in $1 \mathrm{~h}$ at $\sim 11 \mathrm{mM}$, which is considerably less than that reported by Lang et al. (14) but greater than that of Newgard et al. (9) who reported plasma glucose concentration in the portal vein rarely exceeds $8 \mathrm{mM}$ during glucose infusion. The difference in plasma glucose concentration between the portal and arterial blood were not significant as would be expected in the fasted state (Fig. 5). The specific activity of plasma glucose in the portal vein and in the aorta showed time dependent increase during the entire period of infusion (Fig. 6). Unlike Newgard et al. (9) who showed that the specific activity of plasma glucose concentration equals that of glucose in the infusion medium, we found that the specific activity of plasma glucose can reach only as high as $80 \%$ of that in the infusing medium. Further, the specific activity of plasma glucose in either the artery or the portal vein is not constant during the infusion.

The weighted mean specific activity of plasma ${ }^{3} \mathrm{H}$ - and ${ }^{14} \mathrm{C}$-labeled glucose in the portal vein as well as RSA of liver glycogen at the end of $3 \mathrm{~h}$ of infusion were shown in Table III. The percent contribution of the indirect pathway which was calculated by substracting the RSA of $\left[{ }^{3} \mathrm{H}\right]$ glycogen from that of $\left[{ }^{14} \mathrm{C}\right]$ glycogen show that the majority of glycogen synthesis in liver is brought about by the direct pathway.

\section{Discussion}

In this report, we found that liver can extract glucose from blood plasma when glucose concentration in the portal vein exceeds $8 \mathrm{mM}$, a concentration consistent with the reported $K_{\mathrm{m}}$ of glucokinase (24). Plasma glucose concentration in the portal vein at or above this level is routinely attainable in the postprandial state in meal-fed rats. We also found that the ratio of ${ }^{3} \mathrm{H} /{ }^{14} \mathrm{C}$ in glucosyl units of hepatic glycogen after intraportal injection or intravenous infusion of $\left[3-{ }^{3} \mathrm{H}, \mathrm{U}-{ }^{14} \mathrm{C}\right]-$ glucose is $\sim 80-90 \%$ of that found in plasma glucose, indicating that little scrambling of glucose carbon occurs during the incorporation of glucose into liver glycogen. Our data oppose the so-called "glucose paradox" $(6,7)$ which states that glucose can not be utilized efficiently through glycolysis in liver, and that liver glycogen is synthesized from $\mathrm{C}_{3}$ intermediates via the "indirect pathway" $(6,7)$. Our data also contradict several recent reports $(9,10,13,14)$ which showed that no more than one third of the glycogen synthesized in the liver is from the direct pathway $(9,13)$ and that at physiological concentration of plasma glucose the majority of the glycogen is synthesized from the indirect pathway (14). Reasons for the discrepancy between this data base of published work and our results will now be discussed.

Both Newgard et al. (9) and Lang et al. (14) used doubly labeled glucose in their study on the indirect pathway for glycogen synthesis. The difference in the rate of metabolism between an irreversible tracer $(25)$ such as $\left[3-{ }^{3} \mathrm{H}\right]-$ or $\left[6-{ }^{3} \mathrm{H}\right]-$ glucose and a reversible tracer $(25)$ such as $\left[{ }^{14} \mathrm{C}\right]$ glucose has been commonly used in studies on substrate cycling in glucose metabolism (12). Thus, the difference in the rate of metabolism between $\left[2-{ }^{3} \mathrm{H}\right]-$ and $\left[3-{ }^{3} \mathrm{H}\right]$ glucose has been used to indicate the extent of futile cycling between glucose and glucose- 
Table II. Incorporation of Intraportally Injected $\left[3-{ }^{3} \mathrm{H}, \mathrm{U}-{ }^{14} \mathrm{C}\right]$ Glucose into Liver Glycogen*

\begin{tabular}{|c|c|c|c|c|c|}
\hline \multirow[b]{2}{*}{ Diet } & \multirow[b]{2}{*}{${ }^{3} \mathrm{H} /{ }^{14} \mathrm{C}$ in glycogen } & \multirow{2}{*}{$\begin{array}{c}{ }^{3} \mathrm{H} /{ }^{44} \mathrm{C} \text { in liver } \\
\text { free glucose }\end{array}$} & \multirow[b]{2}{*}{ Content of glycogen } & \multicolumn{2}{|c|}{ Rate of glycogen synthesis ${ }^{\ddagger}$} \\
\hline & & & & {$\left[3-{ }^{-3} \mathrm{H}\right]$ glucose } & [U- ${ }^{14} \mathrm{C}$ ]glucose \\
\hline & & & $\mu \mathrm{mol} / \mathrm{g}$ & \multicolumn{2}{|c|}{$\mu \mathrm{mol} / \mathrm{g} / 6 \mathrm{~min}$} \\
\hline $100 \%$ chow & $7.96 \pm 0.25$ & $9.58 \pm 0.06$ & $45.8 \pm 3.3$ & $2.45 \pm 0.61$ & $2.97 \pm 0.82$ \\
\hline $50 \%$ chow $+50 \%$ glucose & $8.97 \pm 0.24$ & $9.75 \pm 0.04$ & $73.3 \pm 18.8$ & $6.05 \pm 2.67$ & $6.43 \pm 2.74$ \\
\hline
\end{tabular}

* Rats were meal-fed diets indicated for $2 \mathrm{~h}$ daily from 8:00 to 10:00 a.m. Data were means $\pm \mathrm{SE}$ of three experiments. $\left[3-{ }^{3} \mathrm{H}, \mathrm{U}-{ }^{14} \mathrm{C}\right] \mathrm{Glucose}$ was injected into the portal vein at the end of meal feeding. Livers were freeze-clamped $6 \mathrm{~min}$ after the injection.

₹ Calculated by dividing the content of radioactivity in liver glycogen (disintegrations per minute per gram) by the specific activity of free glucose (disintegrations per minute per micromole).

6-phosphate (26); the difference in the rate of metabolism between $\left[6-{ }^{3} \mathrm{H}\right]-$ and $\left[3-{ }^{3} \mathrm{H}\right]-$ or $\left[5-{ }^{3} \mathrm{H}\right]$ glucose has been used to indicate futile cycling between fructose-6-phosphate and fructose-1,6-bisphosphate (27); and the difference between the rate of metabolism of $\left[6-{ }^{3} \mathrm{H}\right]-$ and $\left[6-{ }^{14} \mathrm{C}\right]$ glucose has been used to indicate the Cori cycle and glucose-alanine cycle $(27,28)$. Instead of using the difference between ${ }^{3} \mathrm{H}$ - and ${ }^{14} \mathrm{C}$-labeled glucose in the synthesis of liver glycogen, Newgard et al. (9) and Lang et al. (14) chose the RSA of $\left[{ }^{3} \mathrm{H}\right]$ glycogen to estimate the percent contribution of the direct pathway. They calculated the RSA of labeled glycogen by dividing the specific activity of glucose in glycogen by either the specific activity in the infusing glucose (9) or by the specific activity of glucose found in the plasma $(13,14)$ at the end of the infusion period. Since glycogen is synthesized over the $\mathbf{3 h}$ infusion period, it is obvious that for the calculation of the RSA of glycogen to be meaningful, the specific activity of plasma glucose must be constant from the very beginning of the experiment, and that the specific activity of plasma must be equal to that in the infusing medium at any time during glucose infusion (9). Furthermore, in order for the RSA of glycogen to equal the percent contribution of the direct pathway, glycogenolysis must not occur during the infusion of glucose.

These basic requirements for calculating a meaningful RSA of glycogen are not considered in the study of Newgard et al. (9), Shulman et al. (13) and others (14). Despite similar

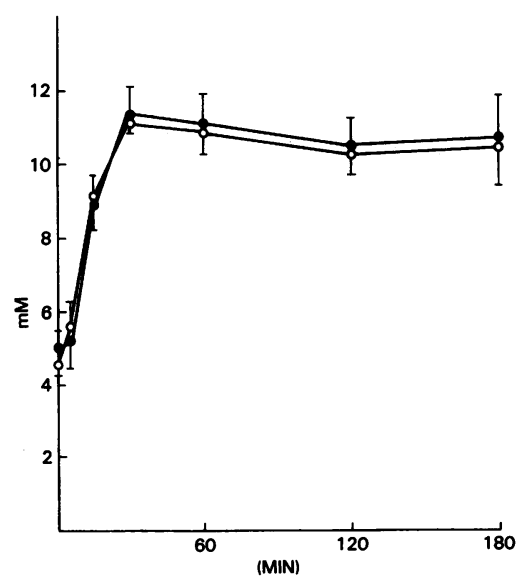

Figure 5. Changes in plasma glucose concentration in arterial (•) and portal (0) blood during glucose infusion. Rats were previously fed ad lib. regular commercial chow diet. They were cannulated and fasted overnight before the experiment. The arterial blood was sampled from a cannula implanted in the aorta from the external carotid artery. The rate of glucose infusion was $1,350 \mu \mathrm{mol} / \mathrm{h}$ per $100 \mathrm{~g}$. Data were mean \pm SE of a group of three experiments. conclusions regarding the importance of the indirect pathway for hepatic glycogenesis between Newgard et al. (9) and Shulman et al. (13), the actual primary data leading to these conclusions from each group are contradictory. Shulman et al. (12) showed that most of the ${ }^{13} \mathrm{C}$ label in glucosyl units of glycogen remained in its original position (82-88\%) during intragastric infusion of $\left[1-{ }^{13} \mathrm{C}\right]$ glucose, while Newgard et al.
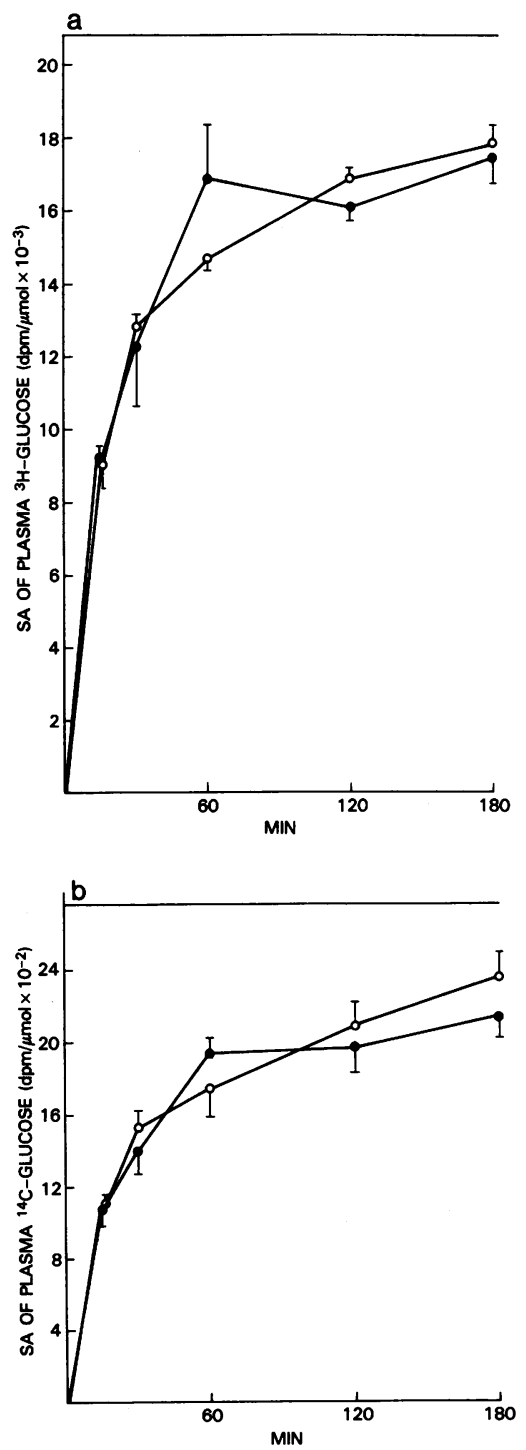

Figure 6. Changes in the specific activity of plasma glucose in the arterial (๑) and portal (o) blood during the in fusion of $\left[3-{ }^{3} \mathrm{H}\right]$ glucose (a) and $\left[\mathrm{U}-{ }^{14} \mathrm{C}\right]$ glucose (b). The rate of glucose infusion and blood sampling were as described in Fig. 5. The rate of infusion of [3${ }^{3} \mathrm{H}$ ]glucose was 13.3 $\mu \mathrm{Ci} / \mathrm{h}$ per $100 \mathrm{~g}$; and for [U $-{ }^{14} \mathrm{C}$ ]glucose was 1.33 $\mu \mathrm{Ci} / \mathrm{h}$ per $100 \mathrm{~g}$. The horizontal line in each figure represents the specific activity of glucose in the infusion medium. Data were mean $\pm S E$ of three experiments. 
Table III. Specific Activity of Liver Glycogen, Plasma Glucose, and the Relative Specific Activity of Glycogen during Intravenous Infusion of $\left[3-{ }^{3} \mathrm{H}, U-{ }^{14} \mathrm{C}\right]$ Glucose ${ }^{*}$

\begin{tabular}{lccc}
\hline & \multicolumn{3}{c}{ Results from } \\
\cline { 2 - 4 } & {$\left[3-{ }^{3} \mathrm{H}\right] g l u c o s e$} & {$\left[\mathrm{U}-{ }^{14} \mathrm{C}\right]$ glucose } & ${ }^{3} \mathrm{H} /{ }^{14} \mathrm{C}$ \\
\hline $\begin{array}{l}\text { SA of liver glycogen } \\
\begin{array}{c}\text { SA of plasma } \\
\text { glucose }\end{array}\end{array}$ & $12,650 \pm 1,100$ & $1,593 \pm 123$ & $7.93 \pm 0.19$ \\
$\begin{array}{c}\text { RSA of liver } \\
\text { glycogen }(\%)\end{array}$ & $14,838 \pm 854$ & $1,830 \pm 110$ & $8.14 \pm 0.50$ \\
& $85.8 \pm 9.4$ & $87.1 \pm 6.6$ & \\
\hline
\end{tabular}

* Glucose was infused at a rate of $1,350 \mu \mathrm{mol} / 100 \mathrm{~g}$ per $\mathrm{h}(243$ $\mathrm{mg} / 100 \mathrm{~g}$ per $\mathrm{h}) .\left[3{ }^{3} \mathrm{H}\right] \mathrm{Glucose}$ was infused at a rate of $13.3 \mu \mathrm{Ci} / \mathrm{h}$ per $100 \mathrm{~g}$; [U- ${ }^{14} \mathrm{C}$ ]glucose was infused at a rate of $1.33 \mu \mathrm{Ci} / \mathrm{h}$ per 100 g. The unit for $\mathrm{SA}$ is $\mathrm{dpm} / \mu \mathrm{mol}$. Data were mean $\pm \mathrm{SE}$ of three experiments.

\# Weighted mean specific activity of plasma glucose in the portal vein was calculated according to Lang et al. (14).

using $\left[1-{ }^{14} \mathrm{C}\right]$ glucose showed that only $39-59 \%$ of the ${ }^{14} \mathrm{C}$-label could remain in its original position during the incorporation into liver glycogen. In spite of these differences, both groups of workers concluded that the direct pathway can account for no more than one third of total glycogen synthesis in liver. To reiterate, both Newgard et al. (9) and Shulman et al. (13) failed to consider the nature of constant infusion of labeled metabolites in estimating the RSA of labeled glycogen. By simply dividing the specific activity of glucose in glycogen by that in the plasma glucose or glucose in the infusing solution, they assumed that the specific activity of glucose in plasma can reach a constant level instantaneously following infusion. In our experiment, we found that the specific activity of plasma glucose can not reach a constant level even after a lengthy period of infusion (Fig. 6). Since glycogen is synthesized over a period when the specific activity of plasma glucose varies, the RSA of labeled glycogen determined based on the specific activity of glucose in the infusing medium or plasma glucose at the end of infusion is bound to contain errors leading to serious underestimation.

Lang et al. (13) considered the variability of the specific activity of plasma glucose during constant infusion and correctly used weighted mean specific activity of plasma glucose as the denominator to calculated the RSA of labeled glycogen. This calculation of the RSA of glycogen was a significant improvement over the method of Newgard et al. (9) or Shulman et al. (12). However, the RSA of $\left[{ }^{3} \mathrm{H}\right]$ glycogen can not be used as an indicator for the contribution of the direct pathway as Lang et al. concluded. It should be calculated by comparing the ${ }^{3} \mathrm{H}$ to ${ }^{14} \mathrm{C}$ ratio in liver glycogen with the same ratio in plasma glucose as Lang et al. later noted (see Fig. 6, reference 14). These two ways to quantitate the percent contribution of the direct versus indirect pathway are incompatible.

In our opinion, the percent contribution of the direct pathway in the synthesis of liver glycogen can be best estimated from the difference of the RSA of $\left[{ }^{3} \mathrm{H}\right]$ and $\left[{ }^{14} \mathrm{C}\right]$ glycogen, determined based on the weighted mean specific activity of plasma glucose (Table III). This approach can circumvent the problem of a glycogenolysis and glycogenesis fu- tile cycle (12). Since glycogen like most other metabolites is subjected to constant degradation and synthesis, futile cycling between glycogenolysis and glycogenesis is inherent in the RSA calculated for $\left[{ }^{3} \mathrm{H}\right]$ and $\left[{ }^{14} \mathrm{C}\right]$ glycogen. The effect of such a cycle is significant and can be seen from the data for RSA of $\left[{ }^{14} \mathrm{C}\right]$ glycogen. Since the radioactivity of $\left[{ }^{14} \mathrm{C}\right]$ glucose can not be released by the indirect pathway, RSA of $\left[{ }^{14} \mathrm{C}\right]$ glycogen should be equal to 1 if glycogenesis is the only metabolic process involved in the incorporation of radioactivity from glucose to glycogen. Experimentally, the RSA of $\left[{ }^{14} \mathrm{C}\right]$ glycogen is far less than 1 as the present result and that of Newgard et al. (9) indicated. Nevertheless, the effect of glycogenesis and glycogenolysis can be eliminated from consideration simply by subtraction. In our experiment with glucose infusion (Table III), the difference in the RSA of $\left[{ }^{3} \mathrm{H}\right]$ and $\left[{ }^{14} \mathrm{C}\right]$ glycogen was taken to indicate the contribution of the indirect pathway, since all else is the same for both ${ }^{3} \mathrm{H}$ - and ${ }^{14} \mathrm{C}$-labeled glycogen except that caused by the indirect pathway of glycogen synthesis. We found no significant difference between the RSA of $\left[{ }^{3} \mathrm{H}\right]$ and $\left[{ }^{14} \mathrm{C}\right]$ glycogen, indicating that glycogen is synthesized predominantly from the direct pathway, in spite of the fact that the RSA for $\left[{ }^{3} \mathrm{H}\right]$ glycogen is not $100 \%$.

Newgard et al. (9) reported that the specific activity of plasma glucose can be equal to that of glucose in the infusing solution, indicating that infused glucose can not be diluted by existing glucose in the animal body. Such a result is highly improbable and reflects a highly unphysiological condition. It disregards the fact that there is sizable glucose pool in the body and that glucose in the body is constantly being degraded through glycolysis and synthesized from endogenous substrates through gluconeogenesis in either starved or fed state (27). Although this result was interpreted by Newgard et al. to indicate that the rate of glucose output is completely inhibited by glucose infusion (9), this explanation can not be supported by data in recent reports. Lang et al. (14) showed that glucose infusion has little effect on hepatic output of plasma glucose or on gluconeogenesis. At high rate of glucose infusion (1300 $\mu \mathrm{mol} / \mathrm{h}$ per $100 \mathrm{~g}$ ), glucose output was inhibited by only $33 \%$. In our experiment, the specific activity of labeled glucose in blood plasma can only reach a level of $\sim 70-80 \%$ of that in the infusing solution (Fig. 6), indicating that significant dilution of the infused glucose by endogenous glucose still occurs.

In conclusion, the present study indicates that liver can extract glucose and synthesize glycogen directly from exogenous glucose by phosphorylation in the postprandial state.

\section{Acknowledgments}

The authors like to thank Dr. G. P. Dobson for valuable discussions.

\section{References}

1. Cook, M., and V. Lorber. 1952. Conversion of $1-{ }^{14} \mathrm{C}$-mannose and $1-{ }^{14} \mathrm{C}$-glucose to liver and muscle glycogen in the intact rat. J. Biol. Chem. 199:1-8.

2. Hostetler, K. Y., and B. R. Landau. 1967. Estimation of the pentose cycle contribution to glucose metabolism in tissue in vivo. Biochemistry. 6:2961-2964.

3. Bishop, J. S., R. Steele, N. Altszuler, A. Dunn, C. Bjerknes, and R. C. DeBodo. 1965. Effects of insulin on liver glycogen synthesis and breakdown in the dog. Am. J. Physiol. 208:307-316. 
4. Hers, H. G. 1954. The conversion of fructose- $1-{ }^{14} \mathrm{C}$ and sorbitol- $1-{ }^{14} \mathrm{C}$ to liver and muscle glycogen in the rats. J. Biol. Chem. 214:373-381.

5. Scofield, R. F., K. Kosugi, W. C. Schumann, K. Kumaran, and B. R. Landau. 1985. Quantitative estimation of the pathways followed in the conversion to glycogen of glucose administered to the fasted rat. J. Biol. Chem. 260:8777-8782.

6. Katz, J., and J. D. McGarry. 1984. The glucose paradox. Is glucose a substrate for liver metabolism? J. Clin. Invest. 74:1901-1909.

7. Katz, J., M. Kuwajima, D. W. Foster, and J. D. McGarry. 1986. The glucose paradox. New perspectives on hepatic carbohydrate metabolism. Trends Biochem. Sci. 11:136-140.

8. Jungermann, K., and N. Katz. 1982. Functional hepatocellular heterogeneity. Hepatology. 2:385-395.

9. Newgard, C. B., C. J. Hinsch, D. W. Foster, and J. D. McGarry. 1983. Studies on the mechanism by which exogenous glucose is converted into liver glycogen in the rat. A direct or an indirect pathway? J. Biol. Chem. 258:8046-8052.

10. Newgard, C. B., S. V. Moore, D. W. Foster, and J. D. McGarry. 1984. Efficient hepatic glycogen synthesis in refeeding rats requires continued carbon flow through the gluconeogenic pathway. J. Biol. Chem. 259:6958-6963.

11. Kuwajima, M., C. B. Newgard, D. W. Foster, and J. D. McGarry. 1986. The glucose-phosphorylating capacity of liver as measured by three independent assays. Implication for the mechanism of hepatic glycogen synthesis. J. Biol. Chem. 261:8849-8853.

12. Katz, J., and R. Rognstad. 1976. Futile cycles in the metabolism of glucose. Curr. Topics Cell. Reg. 10:237-289.

13. Shulman, G. I., D. L. Rothman, D. Smith, C. M. Johnson, J. B. Blair, R. G. Shulman, and R. A. DeFronzo. 1985. Mechanism of liver glycogen repletion in vivo by nuclear magnetic resonance spectroscopy. J. Clin. Invest. 76:1229-1236.

14. Lang, C. H., G. J. Bagby, H. L. Blakesley, J. L. Johnson, and J. J. Spitzer. 1986. Plasma glucose concentration determines direct versus indirect liver glycogen synthesis. Am. J. Physiol. 251:E584E590.

15. Hellerstein, M. K., D. J. Greenblatt, and H. N. Munro. 1986. Glycoconjugates as noninvasive probes of intrahepatic metabolism: pathways of glucose entry into compartmentalized hepatic UDP-glucose pools during glycogen accumulation. Proc. Nat. Acad. Sci. USA. 83:7044-7048.

16. Rémésy, C., C. Demgné, and J. Aufrère. 1978. Inter-organ relationships between glucose, lactate and amino acids in rats fed or high carbohydrate of high protein diet. Biochem. J. 170:321-329.

17. Greene, E. C. 1963. Anatomy of the Rat. Hafner Publishing Co., New York and London. 228.

18. Bergmeyer, H. U. 1974. Methods of Enzymatic Analysis. 2nd edition Academic Press, New York and London.

19. Watanabe, H., and J. V. Passonneau. 1973. Factors affecting the turnover of cerebral glycogen and limited dextran in vivo. J. Neurochem. 20:1543-1554.

20. Katz, J., P. A. Wals, S. Golden, and R. Rognstad. 1975. Recycling of glucose by rat hepatocytes. Eur. J. Biochem. 60:91-101.

21. Sable-Amplis, R., and D. Abadie. 1975. Permanent cannulation of the hepatic portal vein in rats. J. Appl. Physiol. 38:358-359.

22. Helman, A., D. Castaing, J. Morin, N. Pfister-Lemaire, and R. Assan. 1984. A new technique for hepatic portal vein catheterization in freely moving rats. Am. J. Physiol. 246:E544-E547.

23. Sloop, C. H., and B. R. Krause. 1981. Portal and aortic blood sampling technique in unrestrained rats. Physiol. Behav. 26:529-533.

24. Sols, A. 1968. Phosphorylation and glycolysis. In Carbohydrates Metabolism and Its Disorders. Vol. 1. F. Dickens, P. J. Randle, and W. J. Whelan, editors. Academic Press, London. 53-87.

25. Katz, J., H. Rostami, and A. Dunn. 1974. Evaluation of glucose turnover, body mass and recycling with reversible and irreversible tracers. Biochem. J. 142:161-170.

26. Clark, D. G., G. B. Storer, and D. L. Topping. 1980. Inhibition of the substrate cycle glucose:glucose-6-phosphate by physiological concentration of fructose in perfused rat liver. Biochem. Biophys. Res. Commun. 93:155-161.

27. Huang, M.-T., and H. A. Lardy. 1981. Effects of thyroid states on the Cori cycle, glucose-alanine cycle, and futile cycling of glucose metabolism in rats. Arch. Biochem. Biophys. 209:41-51.

28. Dunn, A., M. Chenoweth, and L. D. Shaeffer. 1967. Estimation of glucose turnover and the Cori cycle using glucose-6-t-14 C. Biochemistry. 6:6-11. 